\title{
ENSINO MÉDIO INTEGRADO: ESCOLA UNITÁRIA COMO HORIZONTE?
}

\author{
Claudia Maria Bezerra da Silva \\ E-mail: claudiambezerra@yahoo.com.br \\ Universidade Federal de Pernambuco \\ DOI: $10.15628 /$ rbept.2020.9729
}

Artigo submetido em: mar/2020 e aceito em: abr/2020

\begin{abstract}
RESUMO
O presente artigo tem a finalidade de analisar a formação no ensino médio integrado, discutindo-a na perspectiva da escola unitária que concebe a formação humana em sua totalidade. Para os procedimentos de pesquisa foram realizadas a revisão da literatura e a análise de documentos. A coleta de dados ocorreu por meio da aplicação de questionários com professores e pedagogos do Instituto Federal de Educação, Ciência e Tecnologia de Pernambuco/Campus Recife. Os achados da pesquisa sugerem que coexistem entendimentos que apontam para uma formação para o mercado de trabalho e para uma formação propedêutica, o que denuncia uma compreensão parcial ou inexistente dos princípios histórico, filosófico, pedagógico e político do ensino médio integrado, bem como indo de encontro à perspectiva da escola unitária.
\end{abstract}

Palavras-chave: Ensino Médio Integrado. Escola Unitária. Educação Profissional e Tecnológica.

\section{INTEGRATED HIGH SCHOOL: UNITARY SCHOOL AS HORIZON?}

\begin{abstract}
This article had as purpose to analyze the formation of the integrated high school, discussing it from the perspective of the unitary school that conceives of human development in its entirety. For research procedures a literature review and document analysis were performed. Data collection occurred through the application of questionnaires with teachers and pedagogues from the Instituto Federal de Educação, Ciência e Tecnologia de Pernambuco/Campus Recife. The research findings suggest that understandings coexist that point to training for the labour market and for propaedeutic training, which denounces a partial or nonexistent understanding of the historical, philosophical, pedagogical and political principles of integrated high school, as well as going against the perspective of the unitary school.
\end{abstract}

Keywords: Integrated High School. Unitary School. Professional and Technological Education. 


\section{INTRODUÇÃo}

A educação brasileira historicamente é caracterizada pela distinção entre os que pensavam e aqueles que apenas executavam uma função, pautada na formação propedêutica destinada à elite e, para os menos favorecidos socioeconomicamente, uma formação para mão de obra que atenderia às necessidades do mercado. Esse caráter dual vem sendo amenizado com o Decreto $n^{\circ} 5.154 / 2004$, marco regulatório para a integração entre o ensino médio e a educação profissional.

O ensino médio integrado (EMI) constitui a união do ensino médio e da formação profissional, articulando os conhecimentos com o entendimento de que a política assistencialista ou de ajustamento às demandas do mercado de trabalho tendem a ser ultrapassados, dando abertura à autonomia e emancipação humana. Para tanto, propõe a integração de conteúdos a partir do pressuposto de que os saberes estritamente técnicos ou propedêuticos percam espaço, numa concepção em que não se trata de juntar disciplinas e/ou cargas horárias, mas de ter uma organização curricular que relacione internamente os conhecimentos gerais e específicos, a cultura e o trabalho, o humanismo e a tecnologia. (RAMOS, 2010).

Integrar o trabalho e a educação vai ao encontro da perspectiva da escola unitária de Gramsci (2001), que busca romper com a dicotomia entre a educação básica e a técnica, resgatando o princípio da formação humana em sua totalidade. Para isso, tem a concepção do trabalho como princípio educativo, que permite a apropriação e a compreensão dos conhecimentos a partir de uma formação que deve fornecer as bases científicas e tecnológicas que fundamentam a atividade a ser desempenhada. (GRAMSCI, 2001).

Diante do exposto, tomamos como objetivo geral: analisar a formação no ensino médio integrado, discutindo-a na perspectiva da escola unitária que concebe a formação humana em sua totalidade. O foco dessa discussão está no EMI como possibilidade de diminuir a dualidade escolar que amplia 0 fosso educacional existente entre a classe favorecida economicamente e a classe trabalhadora. Desenvolvemos o tema por meio da revisão da literatura e análise de documentos e, como instrumento de pesquisa, utilizamos a aplicação de questionários com professores e pedagogos do Instituto Federal de Educação, Ciência e Tecnologia de Pernambuco (IFPE)/Campus Recife. Como referencial para fundamentar as discussões, pautamo-nos em estudiosos que se dedicam à investigação e produção teórica relacionada à Educação Profissional e Tecnológica (EPT), EMI e escola unitária, como: Ciavatta (2014), Saviani (2007), Gramsci (2001), entre outros.

Para melhor localizar o leitor, o artigo apresenta uma reflexão sobre a histórica dualidade da educação no Brasil, os documentos norteadores para a integração do ensino médio à educação profissional, a concepção de EMI e a perspectiva da escola unitária a partir de Gramsci. Em seguida, o espaço está destinado à apresentação do percurso metodológico da pesquisa e à análise dos dados coletados com os sujeitos e, por fim, estão as considerações finais. 


\section{A HISTÓRICA DUALIDADE DA EDUCAÇÃO BRASILEIRA}

A educação no Brasil é caracterizada por uma dualidade histórica marcada pela formação oferecida que distinguia os que pensavam daqueles que apenas executavam uma função. Foram políticas públicas que se resumiram ao caráter economicista da educação, com uma visão que não conseguia avançar na perspectiva de uma escola unitária para todos e que superasse a divisão entre a formação para o trabalho manual e intelectual estabelecida pelo pensamento da sociedade em classes.

Como exemplo, podemos nos reportar à década de 1940, quando foram instituídas as Leis Orgânicas que segmentaram a educação de acordo com os setores produtivos, separando os que deveriam ter a formação propedêutica para a universidade e os que seriam formados para exercer atividades estritamente ligadas à mão de obra. Na avaliação de Moura (2007), as Leis Orgânicas da Educação Nacional, entre elas a Lei Orgânica do Ensino Industrial - Decreto no 4.073/1942, a Lei Orgânica do Ensino Normal - Decreto no 8.530/1946 e o Decreto-lei 4.048/1942 que criou o Serviço Nacional de Aprendizagem Industrial/SENAI, trouxeram oficialmente o caráter dualista da educação e a função reprodutora da estrutura social valorizada na época.

Com a primeira Lei de Diretrizes e Bases da Educação Nacional (LDB) Lei no 4.024/1961, existiu a possibilidade de acabar com a dualidade, mas a perspectiva ficou apenas na legislação. Apesar da equivalência entre os cursos para que os alunos provenientes do colegial e do ensino técnico pudessem continuar os estudos no ensino superior (BRASIL, 1961), o acesso por meio de processo seletivo continuava em função do domínio de conteúdos propedêuticos, válidos apenas para a formação ofertada à classe dirigente.

Em 1971, por meio da Lei o 5.692/1971, houve uma tentativa de estruturar o nível médio tornando compulsória a profissionalização, porém, mais uma vez, a realidade foi construída de forma distinta. Na prática, as escolas privadas continuaram, em sua absoluta maioria, com os currículos voltados para as ciências, letras e artes visando ao atendimento às elites e, num outro cenário, o sistema público caminhou em favor de uma profissionalização para o mercado de trabalho. (MOURA, 2007).

A partir dos anos de 1980, houve um movimento social que caminhou em busca da educação como direito de todos, sem distinção socioeconômica. Saviani (2008) destaca o encaminhamento de ações que resultaram em políticas educacionais fundamentadas em princípios que pretendiam a emancipação dos sujeitos, como produções teóricas na área acadêmicocientífica e experiências governamentais que despertaram o debate para a construção de projetos a partir dos interesses da classe trabalhadora. Esse foi um momento pela democratização da educação marcado pela participação da comunidade e com apoio de parlamentares, buscando assegurar uma formação básica que superasse a dualidade existente.

Mas apesar desse esforço, alguns anos depois, o Decreto $\mathrm{n}^{\circ}$ 2.208/1997 colocou para o ensino médio um sentido puramente propedêutico, 
tendo em vista a oferta de cursos técnicos nas formas concomitante e subsequente. Com isso, a dualidade tornou-se legalmente uma prescrição oficial, ao ponto de a educação profissional ser configurada como um subsistema do sistema público de educação, voltado para a formação do trabalhador e sem a elevação do nível de escolaridade.

A necessidade de um ensino médio que pudesse possibilitar ao aluno a consolidação da formação unitária e politécnica ou omnilateral, centrada no trabalho, na ciência, na tecnologia e na cultura, foi apontada apenas anos mais tarde no Decreto oㅜ 5.154/2004, que revogou o Decreto no 2.208/1997, trazendo a possibilidade de integrar o ensino médio à educação profissional técnica. Protagonizaram esforços para esse decreto alguns pesquisadores, entre os quais podemos citar Gaudêncio Frigotto, Maria Ciavatta, Marise Ramos e Dermeval Saviani, que referenciam suas afirmações em filósofos e educadores como Marx, Engels e Gramsci, que defendem os princípios da escola humanista e da formação integral, pública e de qualidade para todos.

Posteriormente, o Decreto ํo 5.154/2004 ainda sofreu alterações importantes feitas por meio do Decreto o 8.268/2014, que incluiu algumas premissas, entre elas a que indica que a educação profissional deverá observar a centralidade do trabalho como princípio educativo e a indissociabilidade entre teoria e prática, atribuindo uma formação mais humana e integral.

A formação integrada significa, portanto, recuperar no contexto histórico e sob uma correlação de forças entre classes, uma concepção relacionada à luta pela superação do dualismo estrutural da sociedade e da educação brasileira em defesa da democracia. Para isso, o EMI seria como uma base unitária que respeita a diversidade da realidade social, oferecendo aos alunos a ampliação dos seus projetos futuros por meio da formação básica e profissional.

Esses avanços nas políticas públicas, que reconhecem a importância de proporcionar uma formação integral, ganhou apoio com a Lei $n^{\circ}$ 11.892/2008 que instituiu a Rede Federal de Educação Profissional, Científica e Tecnológica, criando os Institutos Federais (IF's). As instituições, além de ofertar o EMI, tem por obrigatoriedade da lei que reservar a cada exercício o mínimo de $50 \%$ das vagas para a modalidade (BRASIL, 2008), o que demonstra ênfase e valorização à formação.

Os IF's foram formados a partir das antigas Escolas Técnicas Federais, Escolas Agrotécnicas Federais e dos Centros Federais de Educação Tecnológica, tendo como uma de suas finalidades:

Art. 6ำ Inciso I - ofertar educação profissional e tecnológica, em todos os seus níveis e modalidades, formando e qualificando cidadãos com vistas na atuação profissional nos diversos setores da economia, com ênfase no desenvolvimento socioeconômico local, regional e nacional. (BRASIL, 2008). 
A possibilidade da preparação para o trabalho tendo um significado mais amplo do que simplesmente para um emprego é apontada na LDB no 9.394/1996 que traz no $\S 2^{\circ}$ do Artigo $1^{\circ}$ que "A educação escolar deverá vincular-se ao mundo do trabalho e à prática social", tendo como finalidade apresentada no Artigo $2^{\circ}$ "[...] o pleno desenvolvimento da pessoa, seu preparo para o exercício da cidadania e sua qualificação para o trabalho". E ainda no Artigo 36 - A que "[...] o ensino médio, atendida a formação geral do educando, poderá prepará-lo para o exercício de profissões técnicas". (BRASIL, 1996).

Esses fragmentos permitem a reflexão sobre educação e trabalho como importantes quando se pensa num espaço de construção da emancipação humana. Nesse contexto, o EMI pode ser um meio de formação que habilite o sujeito a desempenhar com competência e autonomia intelectual as suas atribuições, desenvolvendo permanentemente as aptidões para a vida produtiva e social.

\section{DOCUMENTOS NORTEADORES PARA A INTEGRAÇÃO DO ENSINO MÉDIO À EDUCAÇÃO PROFISSIONAL}

Estabelecido a partir do Decreto $n^{0}$ 5.154/2004, o EMI tem no Documento Base da Educação Profissional Técnica de Nível Médio Integrada ao Ensino Médio, publicado em 2007, uma referência que aborda seus princípios e fundamentos, subsidiando a implementação da política pública nas escolas. Como ideia geral, o documento aborda as concepções e as bases pedagógicas do EMI tendo como perspectiva a formação humana integral do aluno, compreendendo a integração entre os conhecimentos técnicos e científicos como elemento fundamental para a superação da dualidade "[...] estrutural entre cultura geral e cultura técnica ou formação instrumental (para os filhos da classe operária) versus formação acadêmica (para os filhos das classes média-alta e alta)". (BRASIL, 2007, p. 25).

Outro movimento importante foi a elaboração das Diretrizes Curriculares para a Educação Técnica de Nível Médio, por meio da Resolução no 06/2012. As diretrizes correspondem ao conjunto articulado de princípios e critérios a serem observados pelos sistemas de ensino e instituições na organização, planejamento, desenvolvimento e avaliação do EMI e seus respectivos itinerários formativos. Entre os princípios norteadores, a resolução indica a relação e articulação entre a formação desenvolvida no ensino médio e a preparação para o exercício das profissões técnicas, o trabalho como princípio educativo, a pesquisa como princípio pedagógico e a utilização de estratégias educacionais como a contextualização, a flexibilidade e a interdisciplinaridade para integração teoria/prática (BRASIL, 2012a). Destaca-se, também, a orientação da organização por eixos tecnológicos, possibilitando itinerários formativos flexíveis, diversificados e atualizados. (BRASIL, 2012a).

Essas são políticas públicas que fortalecem e orientam as ações no EMI, estritamente necessárias para a materialidade de uma modalidade que se constitui, em termos de sua concepção, estrutura e formas de 
organização, com a finalidade de atender aos conhecimentos do ensino médio e à preparação para o trabalho em um mesmo currículo. A dupla função confere à escola a necessidade de ter clareza dos princípios histórico, filosófico, pedagógico e político do EMI para desenvolver um trabalho que garanta ao aluno a aquisição de saberes e competências necessários ao exercício profissional e da cidadania.

\section{O ENSINO MÉDIO INTEGRADO}

A concepção de EMI é de uma formação que contemple o aprofundamento dos conhecimentos científicos produzidos e acumulados historicamente pela sociedade, integrando as dimensões humanas e tecnológicas. Para tanto, tem como horizonte uma educação tecnológica, omnilateral ou politécnica (CIAVATTA, 2014; FRIGOTTO, 2005; RAMOS, 2017; SAVIANI, 2007), que busca recuperar no atual contexto uma escola que seja unitária e sem distinção de classe social.

Cabe destacar que os termos educação politécnica, tecnológica, omnilateral e escola unitária não são sinônimos, mas pertencem ao mesmo campo de ações educativas que têm como meta a superação do dualismo da sociedade e da educação brasileira em defesa da democracia e da escola pública. (CIAVATTA, 2014).

Dessa forma, a educação politécnica valoriza o domínio dos fundamentos científicos das diferentes técnicas utilizadas na produção moderna, mediante a incorporação da dimensão intelectual ao trabalho produtivo (SAVIANI, 2007). Esse ideário aponta, ainda, para o desenvolvimento de todas as potencialidades do aluno, indo ao encontro da concepção de formação humana omnilateral, que configura um processo educacional que contempla "[...] os sujeitos em todas as direções". (RAMOS, 2017, p. 29).

Frigotto (2005) contribui para o debate, trazendo que a educação politécnica ou tecnológica busca desenvolver os fundamentos das diferentes ciências que facultem aos alunos a capacidade analítica das relações sociais e dos processos técnicos do sistema produtivo. É uma formação humana que "[...] rompe com as dicotomias geral e específico, político e técnico ou educação básica e técnica, heranças de uma concepção fragmentária e positivista da realidade humana". (FRIGOTTO, 2005, p. 74).

Portanto, as abordagens apontam para uma visão diferente de quando a formação é um mero treinamento em uma técnica, sem o conhecimento dos seus fundamentos ou articulação com o conjunto do processo produtivo. São convergentes de modo a obter uma escola unitária que, para Gramsci (2001), pode superar a dualidade entre a formação para o trabalho manual e para 0 trabalho intelectual.

As contribuições sugerem que o EMI possa ser organizado de forma a permitir a apropriação significativa e contextualizada dos conhecimentos escolares mantendo a íntima relação com a vida profissional, social e cultural. O ensino, nessa perspectiva, pode desenvolver nos alunos a capacidade de 
compreensão da realidade em que vivem, explorando a possibilidade de trabalhar problemas que sejam complexos e reais.

\section{1 A PERSPECTIVA DA ESCOLA UNITÁRIA}

Ao abordar a relação entre trabalho e educação, Gramsci (2001) atribui ao processo por meio do qual o homem adquire as condições de humanização, influenciado pela história e pelos modos de produção da existência. Nesse processo, a escola unitária seria uma alternativa para a integração entre trabalho, ciência e cultura, originando uma escola essencialmente humanista. (GRAMSCI, 2001).

A perspectiva da escola unitária tem o fundamento da formação politécnica, concebendo o trabalho como princípio educativo (GRAMSCI, 2001) para a apropriação e a compreensão dos conhecimentos. Esse ideário busca romper com a dicotomia entre a educação básica e a técnica, resgatando o princípio da formação humana em sua totalidade, a partir da adoção de uma escola única, destinada a todos os alunos e que propiciasse:

[...] uma cultura geral, humanista, formativa, que equilibre equanimemente 0 desenvolvimento da capacidade de trabalhar manualmente (tecnicamente, industrialmente) e o desenvolvimento das capacidades de trabalho intelectual. (GRAMSCI, 1988, p. 118).

Para Gramsci (2001), a escola unitária é desinteressada, criadora, ativa e busca articular a formação do sujeito para transformá-lo em "especialista + político". Além disso, deve ser ofertada na esfera pública para que o estado arque com todos os custos, tendo em vista que "[...] somente assim ela pode abarcar todas as gerações, sem divisões de grupos ou castas". (GRAMSCI, 2001, p. 36). Em termos epistemológicos e pedagógicos, o ensino proposto na escola unitária deve integrar ciência, cultura, humanismo e tecnologia, sendo necessário que a prática dos professores seja cada vez mais afastada da mera transmissão de conteúdos e técnicas e tenha a intencionalidade de que, através da ação educativa, os indivíduos compreendem enquanto vivenciam e constroem a própria formação.

Assim, somente uma educação que valorize o trabalho nas suas dimensões técnica, científica e política pode estar comprometida com a formação plena, combatendo o pragmatismo utilitarista que legitima a privação sofrida nas sociedades fundadas na divisão das classes sociais e pela concepção do homem como força produtiva.

A escola unitária expressa o princípio da educação como direito de todos, com importante papel na construção de uma práxis transformadora e libertadora, difusora do saber e preparadora da plena existência humana, tendo condições de elaborar, junto aos menos favorecidos da sociedade, instrumentos necessários à conquista da cidadania. 


\section{METODOLOGIA}

A fundamentação desta pesquisa foi pautada pelo método dialético e abordagem qualitativa, buscando construir uma relação dialógica que considerou os determinantes históricos, econômicos, políticos e culturais para subsidiar a reflexão sobre a formação no EMI. O propósito aqui não foi o de contabilizar quantidades como resultado, mas de interpretar as respostas dos sujeitos, contextualizando-as num processo de reflexão contínua.

A construção teórica foi realizada por meio de revisão da literatura e análise de documentos, 0 que propiciou novos conhecimentos $e$ aprofundamento em relação ao objeto de estudo. A revisão da literatura permitiu 0 conhecimento a partir de enfoques de diferentes autores, estabelecendo um diálogo reflexivo entre as abordagens e o tema pesquisado, além de construir uma base teórica que fundamentou os dados coletados no campo. Em relação à análise de documentos, o levantamento do material ocorreu tendo como fontes os oficiais do Governo Federal relacionados à temática, entre eles a LDB no 4.024/1961, a LDB no 9.394/1996 e o Decreto no 5.154/2004, que puderam auxiliar na historicização e compreensão da educação no Brasil.

Sobre o campo de pesquisa, o Campus Recife é o maior e mais antigo do IFPE, com origem que remonta ao ano de 1910. Atualmente, a Instituição conta com 18 cursos distribuídos em: técnico integrado, técnico subsequente, técnico proeja, superior tecnológico, bacharelado, licenciatura e pósgraduação. O técnico integrado ou EMI, foco deste estudo, oferta os seguintes cursos: Edificações, Eletrônica, Eletrotécnica, Mecânica, Química, Saneamento e Segurança no Trabalho.

Participaram da pesquisa 56 professores e 5 pedagogos, que preencheram o questionário de coleta de dados. Para escolha dos sujeitos, o critério estabelecido com relação aos professores, foi o de lecionar nos cursos do EMI do IFPE/Campus Recife, englobando assim, os professores das disciplinas da formação geral e profissional. Já com os pedagogos, era necessário trabalhar acompanhando o processo de ensino-aprendizagem nos cursos do EMI na Instituição.

A aplicação de questionários com os professores foi feita por meio do Google Forms, com link enviado por e-mail para os 286 docentes que atuavam no EMI na Instituição. Desse número, recebemos o retorno de 56 questionários respondidos. Já com os pedagogos, o questionário foi entregue impresso e pessoalmente a todos os 5 profissionais da Instituição, que preencheram e retornaram com as respostas. O instrumento coletou dados relacionados à formação dos sujeitos e à concepção, experiência e prática profissional no EMI.

A escolha do questionário como instrumento para coleta de dados se justifica pela possibilidade de obter informações de grande número de pessoas em um espaço de tempo curto, além da uniformidade quanto ao vocabulário e ordem das perguntas. Gil (2008) define o questionário como a 
técnica de investigação composta por um conjunto de questões que são submetidas com 0 propósito de obter várias informações como os conhecimentos, as crenças, os sentimentos, os valores, os interesses, as expectativas e o comportamento.

Com os dados coletados, a análise e interpretação procurou dar significado às respostas, vinculando aos objetivos propostos, a partir da categorização e análise de conteúdo que, segundo Bardin (2016), é um instrumento "[...] marcado por uma grande disparidade de formas e adaptável a um campo de aplicação muito vasto: as comunicações." (BARDIN, 2016, p. 37). Nessa perspectiva, os dados foram agrupados através da utilização de uma frase, em que foi possível fazer emergir do texto uma unidade temática com base na referência da pesquisa, consistindo em um momento essencial e de reflexão crítica, para atribuir significado às mensagens e compreender as diferentes circunstâncias que influenciaram os discursos.

Sobre o princípio ético, foram seguidas as Resoluções do Ministério da Saúde/Conselho Nacional de Saúde ํㅜ 466/2012 e no 510/2016 no que trata da ética em pesquisa com seres humanos, apresentando a todos os participantes o Termo de Consentimento Livre e Esclarecido com informações e compromisso em zelar pela privacidade e sigilo dos dados. Além disso, a pesquisa foi encaminhada à Plataforma Brasil, tendo sido aprovada pelo Comitê de Ética e Pesquisa da Faculdade Frassinetti do Recife e teve anuência da direção geral do IFPE/Campus Recife para que a coleta de dados fosse realizada na Instituição. Posto isso, todos os dados aqui são apresentados de forma a garantir o anonimato dos sujeitos, sendo identificados da seguinte forma: os professores como P1, P2,...P56; já os pedagogos como $\mathrm{C} 1, \mathrm{C} 2, \ldots \mathrm{C} 5$.

\section{CONCEPÇÕES SOBRE O ENSINO MÉDIO INTEGRADO}

A discussão caminha no sentido de analisar quais são as concepções dos participantes sobre o EMI e se estão ancoradas, de fato, na proposta da modalidade, qual seja a de integrar o ensino médio e a formação profissional na busca da formação humana integral do aluno. Nessa perspectiva, após a análise e interpretação, os dados apontaram para as concepções da formação para o mercado de trabalho, formação justaposta e formação integral, nos levando a refletir que existem pensamentos equivocados sobre a modalidade, que precisam ser revistos.

O EMI ofertante de uma formação para o mercado de trabalho surgiu apontando para a possibilidade de habilitar o aluno tecnicamente para exercer uma profissão, caracterizando o olhar para uma educação voltada meramente ao linear ajustamento às demandas de uma sociedade dual, que necessita de mão de obra qualificada para o aproveitamento imediato no mercado ao término do curso. Foram fragmentos como o do P27 que conceitua o EMI como o que "Trata-se de um ensino médio profissionalizante capaz de fornecer ao mercado uma força de trabalho mais facilmente moldável às suas necessidades." E ainda: "Uma boa opção para o aluno ter uma formação profissional e entrar no mercado de trabalho mais rápido" 
(P45), tendo em vista que se reduz a "Uma formação qualificada para que o aluno exerça uma profissão" (P38). São perspectivas que, conforme Saviani (2007), tendem a reduzir o EMI a um simples adestramento em uma determinada habilidade sem o conhecimento dos seus fundamentos e, menos ainda, da articulação com o conjunto do processo produtivo.

A concepção de que o EMI tem como foco a parte técnica, pode limitar o trabalho do professor a apenas um dos aspectos da modalidade, moldando a formação profissional a uma preparação e ajustamento ao imediatismo das necessidades do mercado que, muitas vezes, centra na preparação para a execução de um determinado conjunto de tarefas de maneira rotineira e burocrática. Coaduna com o histórico da educação no Brasil que ofertava uma educação para o trabalho manual ao cidadão de uma classe socioeconômica menos favorecida, indo de encontro aos esforços para uma educação integrada que pressupõe a superação da dualidade, oportunizando a todos o conhecimento que possibilite o acesso à cultura, à ciência, à tecnologia e ao trabalho por meio da educação básica e profissional.

Uma formação justaposta foi indicada nos dados, o que também remete à necessidade de fundamentação teórica mais embasada sobre o EMI, tendo em vista que a modalidade foi situada no senso comum do caráter da formação básica agrupada à profissional. Os fragmentos apontaram para a concepção de EMI como sendo "De fundamental importância com o diferencial estratégico para quem busca terminar o ensino médio concomitante com um curso técnico" (P9), "Ensino médio e técnicoprofissional concomitantes, com disciplinas das duas formações" (P2) e ainda "Disciplinas do núcleo comum simultâneas as do ensino técnico" (P24). Ao observar a utilização dos termos concomitante e simultâneo, podemos dizer que o EMI foi sinalizado como duas formações que caminham lado a lado, mas sem nenhuma integração, ora assumindo o papel de um ensino propedêutico, que prepara os estudantes para aprovação na universidade; ora para um ensino profissionalizante, que pretende formar mão de obra para o mercado.

Seria a percepção de que as disciplinas do núcleo comum e profissional estão juntas, mas a integração ainda não acontece. Na verdade, - EMI tem como condição prévia que a educação básica dialogue com as mudanças técnico-científicas do processo produtivo (FRIGOTTO, 2005), rompendo com as dicotomias existentes entre geral e específico, relacionadas à concepção dual da educação brasileira. Nesse sentido:

[...] sua identidade como última etapa da educação básica deve ser definida mediante um projeto que, conquanto seja unitário em seus princípios e objetivos, desenvolva possibilidades formativas que contemplem as múltiplas necessidades socioculturais e econômicas dos sujeitos que 0 constituem - adolescentes, jovens e adultos -, reconhecendoos não como cidadãos e trabalhadores de um futuro indefinido, mas como sujeitos de direitos no momento em que cursam o ensino médio. (RAMOS, 2010, p. 48). 
Numa modalidade em que não existe integração entre as formações e disciplinas, surge a possibilidade de práticas isoladas e descontextualizadas, meramente funcional e mecânica, em que ocorre a sobreposição do conhecimento e consequente fragmentação do saber, não atendendo ao interesse na formação humana integral do aluno.

O EMI abrange princípios que devem superar essa dualidade, desenvolvendo possibilidades formativas que possam contemplar as necessidades socioculturais e econômicas dos alunos. Nessa perspectiva, alguns fragmentos apontaram para a formação integral, denotando maior compreensão epistemológica da proposta da modalidade, com falas mais coerentes e objetivas em relação à compreensão da perspectiva da formação humana integral do aluno, como a que podemos visualizar em P46 que afirmou: "O ensino médio integrado, como o próprio nome já diz, integra os diferentes conteúdos e saberes das diferentes áreas, auxiliando na construção do conhecimento pelo aluno de forma efetiva e sistematizada." E ainda: "Acredito que é uma formação numa perspectiva que une os saberes para a produção dos conhecimentos científicos, tecnológicos e cultural, preparando integralmente para a vida e para o mundo do trabalho." (C1); "Tenho a concepção de que é uma modalidade que busca da formação integral do aluno, considerando saberes relacionados à cultura, ao trabalho, à ciência e à tecnologia de forma integrada" (P51). Essas seriam concepções que demonstram recuperar a relação entre educação e trabalho como socialmente necessários, conferindo um maior significado ao exercício profissional e à cidadania dos alunos por possibilitar a compreensão das partes no seu todo. Conforme Ciavatta (2005):

A formação integrada sugere tornar íntegro, inteiro, o ser humano dividido pela divisão social do trabalho entre a ação de executar e a ação de pensar, dirigir ou planejar. Trata-se de superar a redução da preparação para o trabalho ao seu aspecto operacional, simplificado, escoimado dos conhecimentos que estão na sua gênese científicotecnológica e na sua apropriação histórico-social. Como formação humana, o que se busca é garantir ao adolescente, ao jovem e ao adulto trabalhador o direito a uma formação completa para a leitura do mundo e para a atuação como cidadão pertencente a um país, integrado dignamente à sua sociedade política. Formação que, neste sentido, supõe a compreensão das relações sociais subjacentes a todos os fenômenos. (CIAVATTA, 2005, p. 2-3).

O EMI concebido como a união da educação básica com a profissional configura-se como a vinculação de todas as dimensões da vida, sendo uma base para o entendimento crítico de como funciona e se constitui a sociedade humana. Essa concepção de formação compreende que a finalidade da profissionalização não teria fim em si mesmo, muito menos se pautaria pelos interesses do mercado, mas se constitui como uma oportunidade para o aluno construir seu projeto de vida tendo o entendimento de que o homem 
produz sua condição humana pelo trabalho e, por meio dessa ação, transforma o mundo e a si próprio. O trabalho passa, então, a ser uma atividade vital para a vida humana e para a sociedade, retomando a escola como responsável por desenvolver em cada indivíduo a capacidade de pensar e de produzir. Vai ao encontro da proposta da escola unitária que tem por objetivo romper com o caráter marcadamente hegemônico, garantindo formas mais plurais, integradas, críticas e dinâmica. Uma formação humanista, reveladora da mais alta cultura e que favorece o início de novas relações entre trabalho intelectual e trabalho técnico, comum a todos, no intuito de promover um equilíbrio entre formar no aluno a capacidade manual e intelectual. (GRAMSCI, 2001).

No entanto, na prática, a coexistência de entendimentos sobre o EMI encontrada na análise dos dados aponta para concepções que mantém a dualidade de uma formação para o mercado de trabalho e para uma formação propedêutica, denunciando uma compreensão parcial ou inexistente dos princípios histórico, filosófico, pedagógico e político da modalidade. Seria como se, ao compreender a proposta de EMI, os sujeitos utilizassem erroneamente como referência a concepção de composição curricular por justaposição do ensino médio com a habilitação profissional, causando preocupação sobre como está sendo encaminhada a ação dos participantes na Instituição.

O entendimento do conceito de EMI, sobretudo nas suas dimensões pedagógica e política, são importantes para repensar a educação na direção da concepção da escola unitária e seus desdobramentos, sendo uma possibilidade para não reproduzir uma formação propedêutica, puramente técnica ou que não tenha integração entre as áreas. A unidade entre a formação geral e para o trabalho, juntamente com a prática social, darão ao homem condições de formar-se na totalidade das suas faculdades, construindo uma sociedade justa e igualitária.

\section{CONSIDERAÇÕES FINAIS}

A superação da dualidade estrutural histórica, garantindo a todos o direito à educação básica e à formação profissional, demonstra ser alcançada com um EMI capaz de educar cidadãos para compreender e atuar na realidade social em que vivem e no mundo do trabalho de forma ética e competente. É uma formação que tem a concepção de ser omnilateral, politécnica ou tecnológica e de escola unitária, com a finalidade de que a profissionalização não teria fim em si mesmo, mas seria uma possibilidade a mais para o sujeito construir seu projeto de vida, contribuindo para a construção da justiça social, sem segregação na formação educacional.

Os achados da pesquisa sugerem que coexistem entendimentos que apontam para uma formação para o mercado de trabalho e para uma formação propedêutica, o que denuncia uma compreensão parcial ou inexistente dos princípios histórico, filosófico, pedagógico e político do EMI, indo de encontro à perspectiva da escola unitária. Desse modo, colocamos a necessidade da implementação de uma política de formação específica para 
os professores que atuam na modalidade, elaborada a partir de fundamentos teóricos e metodológicos que contemplem a relação trabalho/educação e a formação humana integral do aluno.

O desafio continua sendo a proposta de uma escola de qualidade para todos, sem distinção de classe socioeconômica. Os esforços em garantir o EMI na legislação brasileira e nas experiências em desenvolvimento nos IF's são valorizados, mas ainda há muito a ser feito no sentido de romper com a fragmentação na formação, garantindo, de fato, uma formação integrada e integral, numa escola unitária.

\section{REFERÊNCIAS}

BARDIN, L. Análise de conteúdo. São Paulo: Edições 70, 2016.

BRASIL. Decreto no 2.208, de 17 de abril de 1997. Regulamenta o $§ 2 ~-~ d o$ art. 36 e os arts. 39 a 42 da Lei no 9.394, de 20 de dezembro de 1996, que estabelece as diretrizes e bases da educação nacional. Brasília: Presidência da República, 1997. Disponível em:

http://www.planalto.gov.br/ccivil_03/decreto/d2208.htm. Acesso em: 31 jun. 2019.

BRASIL. Decreto no 5.154, de 23 de julho de 2004. Regulamenta o § 2을 do art. 36 e os arts. 39 a 41 da Lei no 9.394, de 20 de dezembro de 1996, que estabelece as diretrizes e bases da educação nacional, e dá outras providências. Brasília: Presidência da República, 2004. Disponível em: http://www.planalto.gov.br/ccivil_03/_ato2004-2006/2004/decreto/d5154.htm. Acesso em: 31 jun. 2019.

BRASIL. Decreto no 8.268, de 18 de junho de 2014. Altera o Decreto no 5.154 , de 23 de julho de 2004, que regulamenta o $\S 2^{\circ}$ do art. 36 e os arts. 39 a 41 da Lei no 9.394, de 20 de dezembro de 1996. Brasília: Presidência da República, 2014. Disponível em:

http://www.planalto.gov.br/ccivil_03/_Ato2011-2014/2014/Decreto/D8268.htm. Acesso em: 02 jun. 2019.

\section{BRASIL. Educação Profissional Técnica de Nível Médio Integrada ao}

Ensino Médio: Documento Base. Brasília: Ministério da Educação, 2007.

Disponível em:

http://portal.mec.gov.br/setec/arquivos/pdf/documento_base.pdf. Acesso em: 16 jul. 2019.

BRASIL. Lei no 4.024, de 20 de dezembro de 1961. Lei de Diretrizes e Bases da Educação Nacional. Brasília: Presidência da República, 1961. Disponível em: http://www2.camara.leg.br/legin/fed/lei/1960-1969/lei-4024-20-dezembro1961-353722-publicacaooriginal-1-pl.html. Acesso em: 31 nov. 2019.

BRASIL. Lei no 5.692, de 11 de agosto de 1971. Lei da Reforma de Ensino de $1^{\circ}$ e $2^{\circ}$ graus. Brasília: Presidência da República, 1971. Disponível em: http://www2.camara.leg.br/legin/fed/lei/1970-1979/lei-5692-11-agosto-1971357752-publicacaooriginal-1-pl.html. Acesso em: 31 jan. 2020. 
BRASIL. Lei no 9.394, de 20 de dezembro de 1996. Lei de Diretrizes e Bases da Educação Nacional. Brasília: Presidência da República, 1996. Disponível em: www.planalto.gov.br/ccivil_03/leis/L9394.htm. Acesso em: 30 nov. 2019.

BRASIL. Lei no 11.892, de 29 de dezembro de 2008. Institui a Rede Federal de Educação Profissional, Científica e Tecnológica, cria os Institutos Federais de Educação, Ciência e Tecnologia, e dá outras providências. Brasília:

Presidência da República, 2008. Disponível em:

http://www.planalto.gov.br/ccivil_03/_ato2007-2010/2008/lei/l11892.htm.

Acesso em: 12 nov. 2019.

BRASIL. Resolução no 06, de 20 de Setembro de 2012. Define Diretrizes

Curriculares Nacionais para a Educação Profissional Técnica de Nível Médio. Brasília: Ministério da Educação, 2012a. Disponível em:

http://portal.mec.gov.br/index.php?option=com_docman\&view=download\&alia $\mathrm{s}=11663$-rceb006-12-pdf\&category_slug=setembro-2012-pdf\&Itemid=30192.

Acesso em: 10 nov. 2019.

BRASIL. Resolução no 466, de 12 de Dezembro de 2012. Diretrizes e normas regulamentadoras de pesquisas envolvendo seres humanos. Brasília: Ministério da Saúde, 2012b. Disponível em:

http://bvsms.saude.gov.br/bvs/saudelegis/cns/2013/res0466_12_12_2012.htm I. Acesso em: 13 set. 2019.

BRASIL. Resolução no 510, de 7 de abril de 2016. Dispõe sobre normas aplicáveis a pesquisas em Ciências Humanas e Sociais. Brasília: Ministério da Saúde, 2016. Disponível em:

http://bvsms.saude.gov.br/bvs/saudelegis/cns/2016/res0510_07_04_2016.htm I. Acesso em: 13 set. 2019.

CIAVATTA, M. A formação integrada: a escola e o trabalho como lugares de memória e identidade. Trabalho Necessário, Niterói, v. 3, n. 3, p. 01-20, 2005. Disponível em:

http://periodicos.uff.br/trabalhonecessario/issue/view/266. Acesso em: $21 \mathrm{dez}$. 2019.

CIAVATTA, M. O ensino integrado, a politecnia e a educação omnilateral. Por que lutamos? Trabalho \& Educação, Belo Horizonte, v. 23, n. 1, p. 187-205, jan-abr 2014. Disponível em:

http://forumeja.org.br/go/sites/forumeja.org.br.go/files/Ciavatta_ensino_integra do_politecnia_educacao_omnilateral.pdf. Acesso em: 20 dez. $\mathbf{2} 019$.

FRIGOTTO, G. Concepções e mudanças no mundo do trabalho e o ensino médio. In: FRIGOTTO, G.; CIAVATTA, M.; RAMOS, M. (orgs.). Ensino médio integrado: concepção e contradições. São Paulo: Cortez, 2005. p. 5782.

GIL, A. C. Métodos e técnicas de pesquisa social. 6. ed. São Paulo: Atlas, 2008.

GRAMSCI, A. Os intelectuais e a organização da cultura. Rio de Janeiro: Civilização Brasileira, 1988.

GRAMSCI, A. Cadernos do cárcere. Os intelectuais. O princípio educativo. Jornalismo, v. 2, 2. ed. Rio de Janeiro: Civilização Brasileira, 2001. 
MOURA, D. H. Educação básica e educação profissional e tecnológica: dualidade histórica e perspectivas de integração. Holos, Natal, v. 2, ano 23 , p. 4-30, 2007. Disponível em:

http://www2.ifrn.edu.br/ojs/index.php/HOLOS/article/view/11. Acesso em: 21 dez. 2019.

RAMOS, M. Ensino médio integrado: ciência, trabalho e cultura na relação entre educação profissional e educação básica. In: MOLL, J. (org.).

Educação profissional e tecnológica no Brasil contemporâneo: desafios, tensões e possibilidades. Porto Alegre: Artmed, 2010. p. 42-57.

RAMOS, M. Ensino médio integrado: lutas históricas e resistências em tempos de regressão. In: ARAUUJO, A. C.; SILVA, C. N. N. da (orgs.). Ensino médio integrado no Brasil: fundamentos práticas e desafios. Brasília: Ed. IFB, 2017. p. 20-43.

SAVIANI, D. Trabalho e educação: fundamentos ontológicos e históricos. Revista Brasileira de Educação, Rio de Janeiro, v. 12, n. 32, p. 152-165, jan./abr. 2007. Disponível em: http://www.scielo.br/scielo.php?pid=S141324782007000100012\&script=sci_abstract\&tlng=pt. Acesso em: 21 dez. 2019.

SAVIANI, D. História das ideias pedagógicas no Brasil. 2. ed. Campinas: Autores Associados, 2008. 